\title{
Testing Geographical Methodology and Tools for the Study of Territories Damaged by Earthquakes. The Case of L'Aquila and Other Localities Three Years after the April 6th 2009 Event
}

\author{
Cristiano Pesaresi ${ }^{1}$, Gianluca Casagrande ${ }^{2}$, Riccardo Morri ${ }^{1}$ \\ ${ }^{1}$ Dipartimento di Scienze Documentarie, Linguistico-Filologiche e Geografiche, Sapienza University of Rome, Rome, Italy \\ ${ }^{2}$ Geographic Research and Application Laboratory, European University of Rome, Rome, Italy \\ Email: cristiano.pesaresi@uniroma1.it
}

Received October 16, 2012; revised November 19, 2012; accepted December 12, 2012

\begin{abstract}
In this paper, we discuss a geographical methodology supported by specific geo-technologies which we are testing for the study of territories damaged by the L'Aquila earthquake of 6 April 2009 and which can be used in similar situations. Subsequently, we provide an overview of the current situation and make a comparison between some aerial photographs obtained from an overflight in March 2012 and some photos made during our first field study in February 2010, in order to show the work undertaken or not during this period and to substantiate any considerations regarding the choices adopted and the necessary future planning. Moreover, we provide an example of the added value provided by the analysis of aerial photographs in both visible and thermal light for recognizing the provisional non-painted metal roofing of buildings in a post-earthquake urban area. In fact this technique can be useful for the rapid identification of damaged buildings and zones with provisional covering. In the present paper, we focus attention on L'Aquila town centre which provides a significant example of a "City of Stone" almost "minus" the presence of people.
\end{abstract}

Keywords: L’Aquila Earthquake; Aerial Photographs; City of Men; City of Stone; Community; Damages; Geographical Methodology; Geo-Technologies

\section{Introduction}

A disaster which involves urban areas damages both buildings and inhabitants, workers and students living in the town. The human price of such a disaster can be considered on different levels: the deaths are the most important, then the injured and then the many social and economic problems. Loss of relatives and/or friends, the destruction of homes, unemployment and the reduced quality of services (healthcare, transport, education) are the main difficulties normally faced during the weeks and months following the event [1].

But an earthquake like that of 6 April 2009 in L'Aquila also brutally destroys the relationships between the shape of a city and its living spaces.

L'Aquila is a historical city, with a shape that reflected the evolution of settled human groups (and their organization) over the centuries. A town with its own landscape, featuring living space for its inhabitants and city users $[2,3]$.

An earthquake causes a short circuit in the relationship between the material and the immaterial city: usually, rebuilding gradually attempts to reconnect the places with the people. The plan of the town should be drawn according to the image, to the pattern that belongs to a settled community.

The degree of people's confusion proportionally increases with the growth of the distance between plan and pattern. This aspect is very important in a territory of long term settlement, where buildings, squares, boulevards, parks and gardens (along with their reciprocal position and localization in space) influence the public representation of places over time [4,5].

In recent years, geographers, historians and anthropologists studying urban peripheries have drawn attention to the crisis of city planning. The main questions are choices which do not take cognizance of identity and sense of place in the construction (maintenance, management) of "marginal" areas.

Many researches focus on the necessity of emphasising the presence of a community in urban districts. Oral history and biographical approaches allow us to "discover" connections between the meaning of urban artifacts/objects (symbolic value) and people in order to en- 
hance the sense of place and endorse policies of development [6].

A common memory of places shared by a territorial community does exist and it can be registered and documented (using maps, videos, photos and interviews) [7].

The post-event planning in L'Aquila denies both the existence and the importance of this memory, and erases the vital energy of the traditional landscape. Two levels of restriction of the sense of place can be seen in L'Aquila. First of all, the historical town centre has become a ghost, a meaningless area, empty of both people and functions. Also, the building of "new towns" in the suburbs has changed people's way of life, but there has been a falsification of landscape because meaningful living spaces were replaced with anonymous non-places. These choices are not strictly caused by the emergency, but mainly depend on both a misunderstanding of the management of the territory and speculative urban policies in Italy.

The large number of damaged buildings in the historical centre needed carefully selected interventions to prevent people from abandoning their houses and economic activities definitely or for a very long time. A lot of money was wasted in order to avoid demolitions but without any actions being taken for a true revitalization of the town.

Rural suburban areas have changed their land use destination to become urban areas in order to build new permanent settlements. The effects of these policies have been:

- weakness in the relationship territory-community;

- increasing confusion and loss of sense of place;

- abnormal growth in land value;

- creation of anonymous peripheries without any characteristic functions.

People living in the other municipalities damaged by L'Aquila earthquake generally lived in little village communities: for this reason also, the new settlements, named "new towns", are far removed from any real context.

In this paper, using some images obtained with an overflight and some photos made during our first field study, we outline the damages and the situation in L'Aquila three years after the earthquake and the progress made or not made during this time. Moreover, in our research project, we attempt to show how the revolution in the town's shape and the landscape of suburbs has adversely affected the way of life of the inhabitants of L'Aquila. This approach enables us to measure the negative impacts of some planning choices in order to show different kinds of damage management.

Care for the City of Stone in L'Aquila today means restoring its living cultural heritage. After the emergency, the main goal is now a radical development of the Province and of the Region and it will not be possible if the
City of Stone no longer equates with the City of Men. For this purpose, we are testing a geographical methodology supported by the use of different tools and geotechnologies which will be useful both to define a framework with different level of detail and to support suitable future planning, after due consideration of the present problems and necessities.

\section{Geographical Methodology and Tools for the Study of Territories Damaged by the L'Aquila Earthquake}

In 2012 the Geographical Unit (Dipartimento di Scienze documentarie, linguistico-filologiche e geografiche) of the Sapienza University of Rome, in collaboration with the Geographic Research and Application Laboratory (GREAL), European University of Rome, conducted an overflight above the most damaged Abruzzi localities [8].

Primarily, the overflight was carried out in order to:

- form an overview of the situation, in L'Aquila and other municipalities, three years after the earthquake of 6 April 2009;

- recognize weak elements in the urban system, in the density and distribution of the houses, in the materials and building criteria used or not used;

- make an assessment of the work carried out to reestablish safe and practicable conditions in the houses and streets which had been badly damaged;

- examine the placement and characteristics of the new houses which were built during the first phases of the emergency but today generally occupied by people whose houses were defined impracticable;

- evaluate the current status of churches and monuments which embody a very important historical heritage and which are still waiting to be adequately restructured and restored;

- observe the lost vitality of the streets and squares which in the past were the points of social interaction and amusement for local communities and tourists;

- identify areas which require specific attention because of some peculiar aspects or problems;

- test a geographical methodology which attempts to support an interplay between comprehensive observation by aerial photogrammetry and detailed observation in the field.

To test the geographical methodology, we decided to operate in the following ways.

First of all, we decided to direct the overflight (March 2012) over L'Aquila and other municipalities affected by an intensity (MCS) major or equal to 8.5 [9]: Castelnuovo (in the municipality of San Pio delle Camere), intensity 9.5 MCS; Onna (L’Aquila), 9.5; San Gregorio (L’Aquila), 9.0; Sant'Eusanio Forconese, 9.0; Tempera (L’Aquila), 9.0; Villa Sant'Angelo, 9.0; L’Aquila town 
centre, 8.5; Poggio di Roio (L’Aquila), 8.5; Poggio Picenze, 8.5. The overflight, which also involved other nearby localities, had a duration of about 40 minutes and produced about 700 images, taking aerial photographs both in visible and thermal light. The photos were usually taken from an altitude of 800 - 1100 meters, but the resolution permitted various zoom levels, as well as the consultation of GPS data (latitude and longitude).

The aerial photograph in visible and thermal light allowed us to make a mental map of the situation in a very short time, providing the basis for many considerations, e.g.:

- have an idea of the general damage status three years after the earthquake;

- focus attention on specific elements, potential risks and critical zones, also in anticipation of follow-up field studies;

- make comparisons with some photos which we made during our first field study (February 2010), together with some colleagues of the University of Poitiers (France) and with the support of the Department of Civil Protection and Fire Brigade [10].

After organizing an archive of material, with different folders on each of the areas examined, of damage types and different levels of collapse, etc., we began analysing the images. The aerial photographs in visible light, thanks to their ease of interpretation compared with orthogonal images, allowed us to identify important information at different geographical scales, while the thermal photos enabled us to make particular investigations and checks (i.e. on the material of the roofs).

As a second step, to have further details and to be sure of having precisely identified the area shown in the photos, we inserted the geographical coordinates indicated in the GPS data into Google Earth, which shows the place where the photos were made. In this manner, we also compared our images with those of Google Earth to better understand certain changes and features.

As a third step, we are preparing specific forms for some relevant photos, in order to have accessible and upgraded materials useful for our research, as well as for educational purposes, since they involve geographical and historical information, GIS elaborations, data regarding the use of soil, comments on damages, urban plans, weak and strong elements, priorities to adopt, etc.

As a fourth step, we marked out a suitable itinerary and the main stages of a subsequent field study which will be important in that will let us view directly and more closely the aspects obtained by aerial photogrammetry. We have selected L'Aquila town centre because it continues to be a very interesting laboratory for researchers from different scientific sectors (such as geography, geology, economics, history, engineering, urban planning, etc.), and shows worrying signs of a far too slow restora- tion of its social and economic activities; we have chosen Castelnuovo, Onna, Sant'Eusanio Forconese, Tempera and Villa Sant'Angelo since they recorded a very high seismic intensity and a very marked degree of damage; San Gregorio since it appears to be uninhabited in the old centre but some aspects let us to think that people are trying to restore their sense of identity. In order to reach almost inaccessible places, and conduct a further evaluation from another point of view and to rapidly obtain information regarding roofs and upper floors, domes, bell towers, castles, etc., we will carry out our field study with the help of a remote-control helicopter equipped with a digital camera (Figure 1). Therefore, the interplay between different tools and various kinds of geographical observation allow us to test out an articulate geographical methodology for the study of territories damaged by earthquakes.

\section{An Overflight above L'Aquila Town Centre}

The overflight conducted in March 2012 shows an uncertain situation with heavy and widespread damage to houses and to historical buildings as previously indicated by different studies [11,12].

Particularly, the masonry structures have suffered the most severe damage both in L'Aquila town centre and surrounding localities due to problems of connection between walls, floors and roofs, out-of-plane wall collapses and shear failure of wall piers [13-15]; nevertheless, various reinforced buildings having non-ductile moment frames were also subjected to relevant damage [12,15].

L'Aquila town centre continues therefore to appear as a wounded and heavily damaged environment where the time needed for a general re-vitalization is extensive. For example, if we focus our attention on the area near the church of S. Pietro a Coppito, we observe a marked level of damage in a context of neglect without people. In this case, the earthquake, whose effects were enhanced by different factors of vulnerability, provoked severe damage

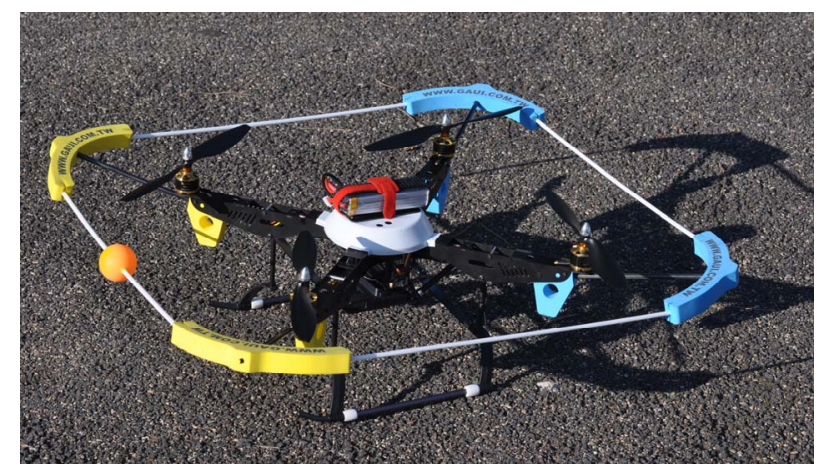

Figure 1. The remote-control helicopter equipped with a digital camera which will be used during the next field study. Photo by GREAL. 
and partial collapse to the front of the church, to the nave and belfry [16]. Now, the church shows the signs of safety measures having been taken, but not the signs of structural and functional restructuring; and the nearby buildings show yielding and cave-in signs or temporary patching and covering of the roofs which denote an evident dereliction status (Figures 2 and 3). A comparison with some photos of February 2010 (Figures 4 and 5) certainly indicates the present lack of confusion and the scant presence of rubble which two years before filled the square. But from a structural point of view, the general framework is not very different, since work for reducing the risk of further and dangerous settling has been carried out (i.e. breaking down the unsafe walls of the building located on the left side of the church) but organic and decisive action for restoration were not taken. Consequently, many buildings are subject to wear and tear and some of them continue to have openings in their perimeter walls (i.e. the pink building on the left in Figure 3).

The same atmosphere, characterized by an unusual and eerie sense of inactivity, can be felt everywhere along the town centre streets and squares of L'Aquila. For example (Figure 6), a general view of the zone between the Piazza del Duomo (partially on the left) and Piazza del Palazzo (on the right) shows numerous works of propping, provisional patching and waterproof covering of the roofs, sometimes reinforced with beams (i.e. the building with light blue cover on the left). This situation, which shows relevant works of safety measures, still awaits planning which can provide for a definitive restart, since at the moment the work does not seem "in progress" and the situation is similar to two years before. In fact, the comparison between the photos of March 2012 (Figure 7) and February 2010 (Figures 8 and 9), focused on Palazzo Madama (in Piazza del Palazzo) and nearby streets (Via Bafile and successively Via Roma, on the right of Palazzo Madama), continue to show thick struts and also partial collapses (behind, on the right in Figure 7). These safety measures might represent the first step in the immediate post-emergency phase, but they did not seem sufficient in February 2010 [10] and they are absolutely inadequate three years after the earthquake because new practical steps have to be taken to give confidence to the people, to re-establish necessary balances, to promote a social and economic resumption and to recoup an important living and historical heritage.

\section{Recognizing Provisional Non-Painted Metal Roofing of Buildings in a Post-Earthquake Urban Area by Examination of Thermographic Frames}

As part of the methodology of this research, we tested a specific procedure for the recognition of provisional nonpainted metal roofing of buildings in L'Aquila, as an example of a post-earthquake urban area, by examining

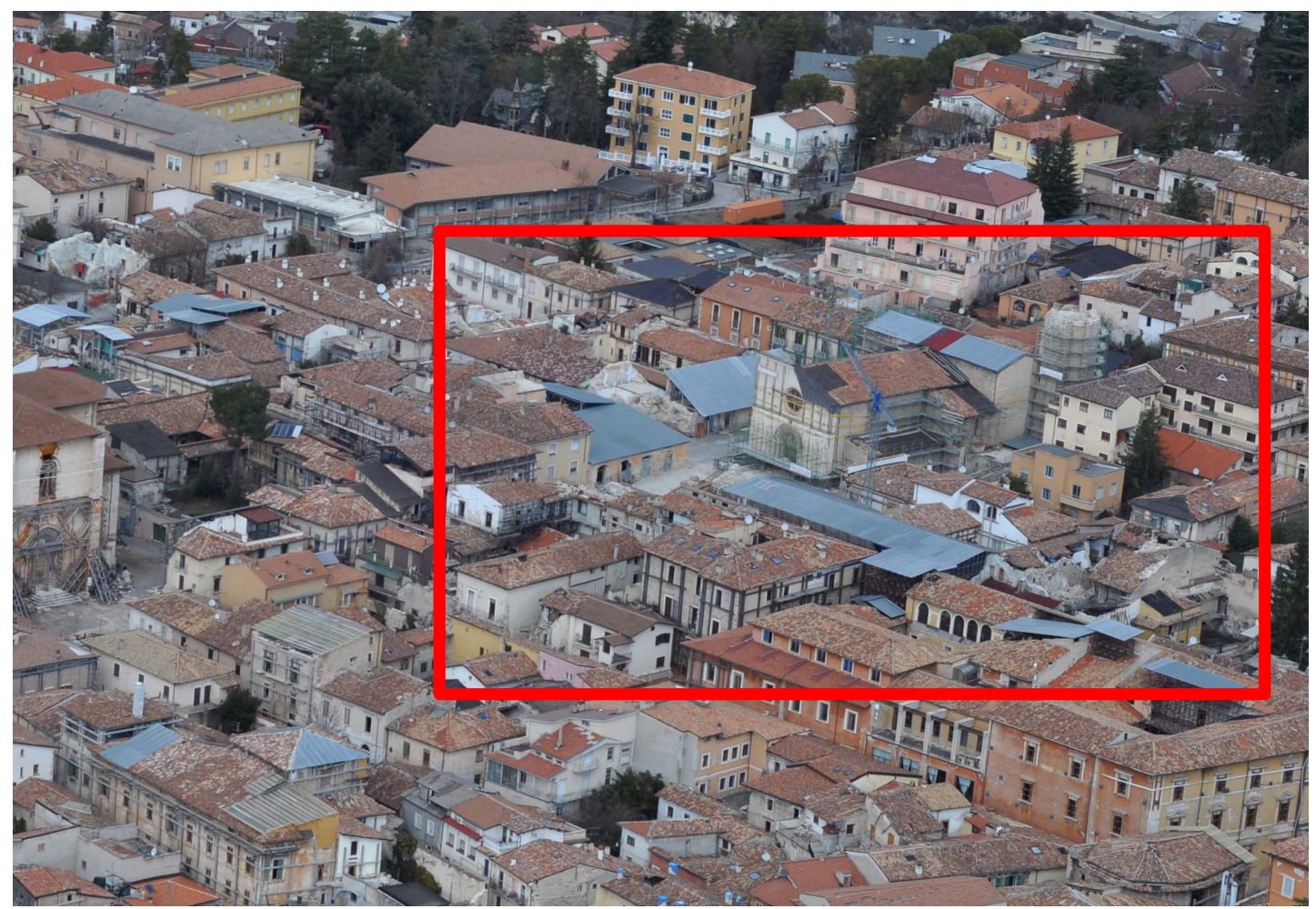

Figure 2. The church of S. Pietro a Coppito and the nearby buildings in March 2012. 


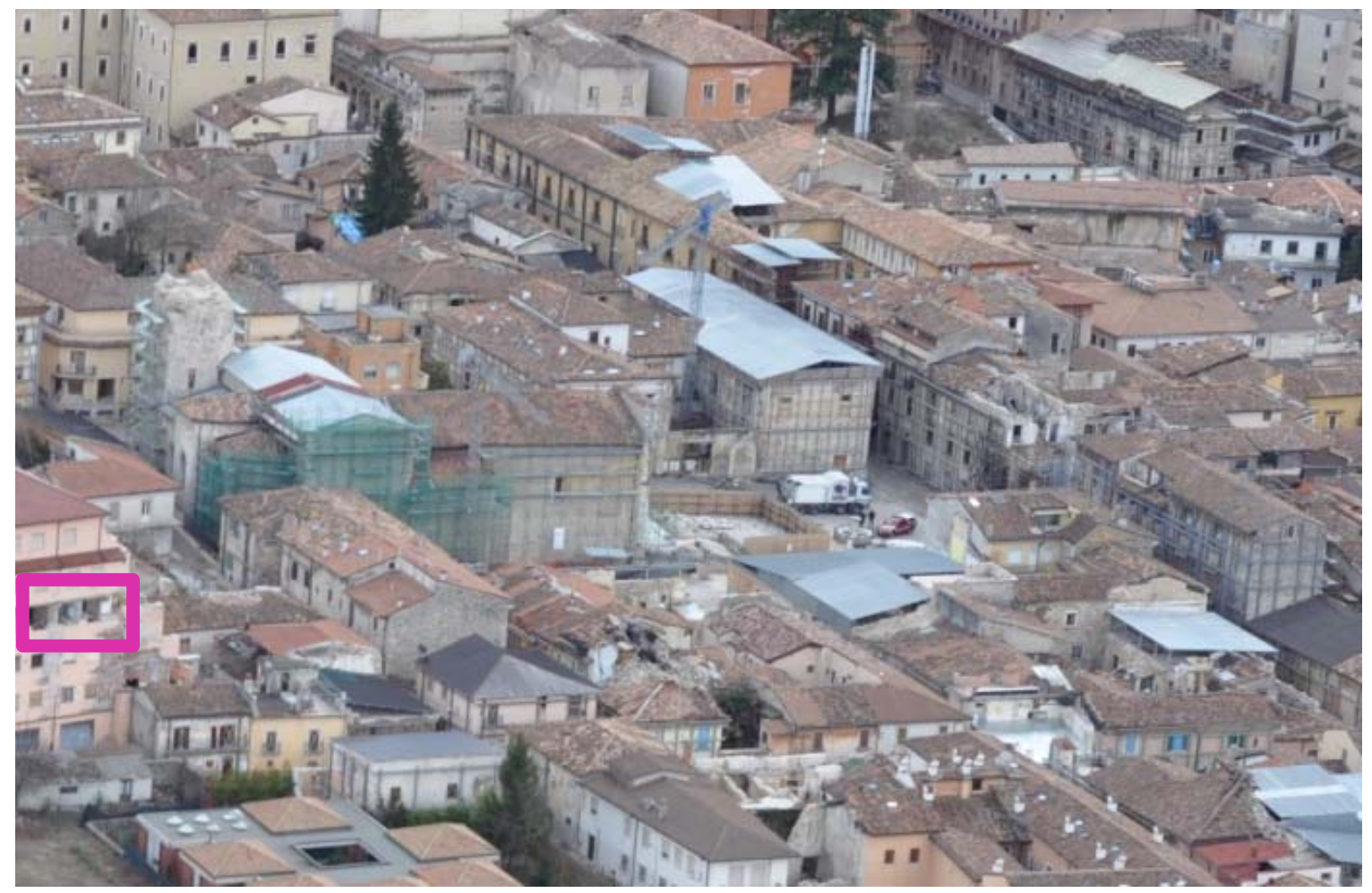

Figure 3. The situation in proximity of the church of S. Pietro a Coppito in March 2012.

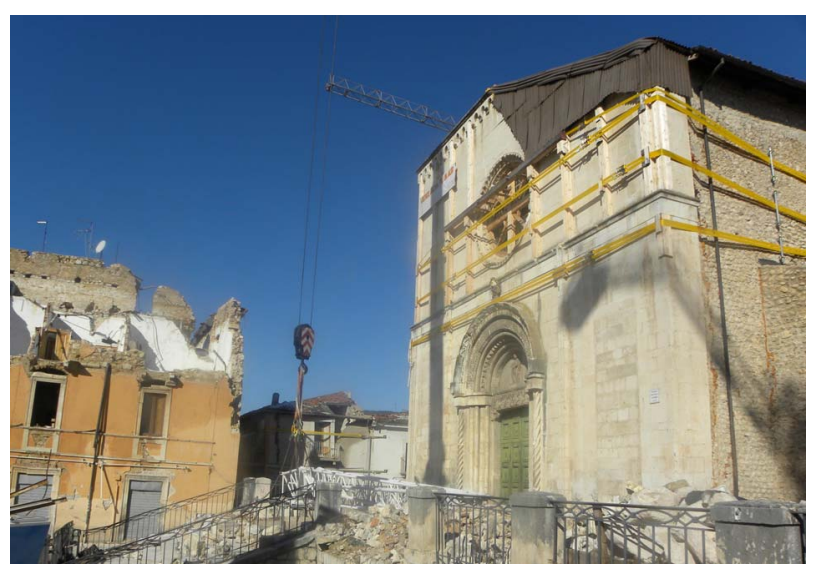

Figure 4. The church of S. Pietro a Coppito in February 2010. Photo by C. Pesaresi.

thermographic frames. The procedure is based on the comparison between visible and infra-red light images. In a manual interpretation conducted by human analysts, thermal frames can be used to cross-check the interpretation of visible-light images; however, it would be also possible to perform the recognition directly on the thermal frames and later validate it by referring to the visible light images. This second approach would be more appropriate for an automated analysis process, operating on a large number of images under human operator supervision.

Depending on its local temperature, every material sur-

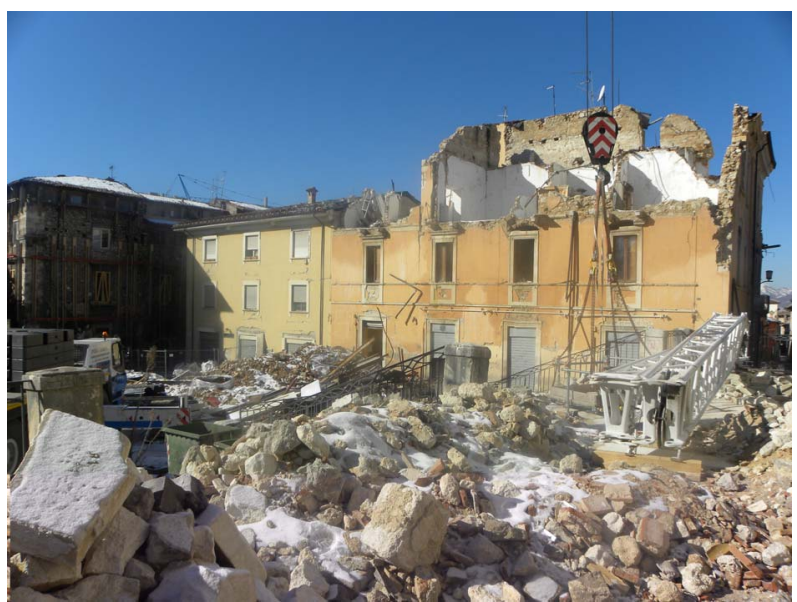

Figure 5. Some buildings near the church of S. Pietro a Coppito in February 2010. Photo by C. Pesaresi.

face emits a specific radiation in a section of the thermal infrared portion of the electromagnetic spectrum (wavelength 0.75 to $14 \mu \mathrm{m}$ ) [17]. Such radiation can be captured by an appropriate sensor, called a "thermal-camera". The camera translates the intensity of the radiation received by each detecting unit of the sensor, into quantitative values which are then used to render a false-colour graphic "image" of the "thermal scene" in front of the camera. In standard, ground-based thermography it is possible to detect the presence of warmer or cooler objects in contexts whose temperature is different. This is possible 


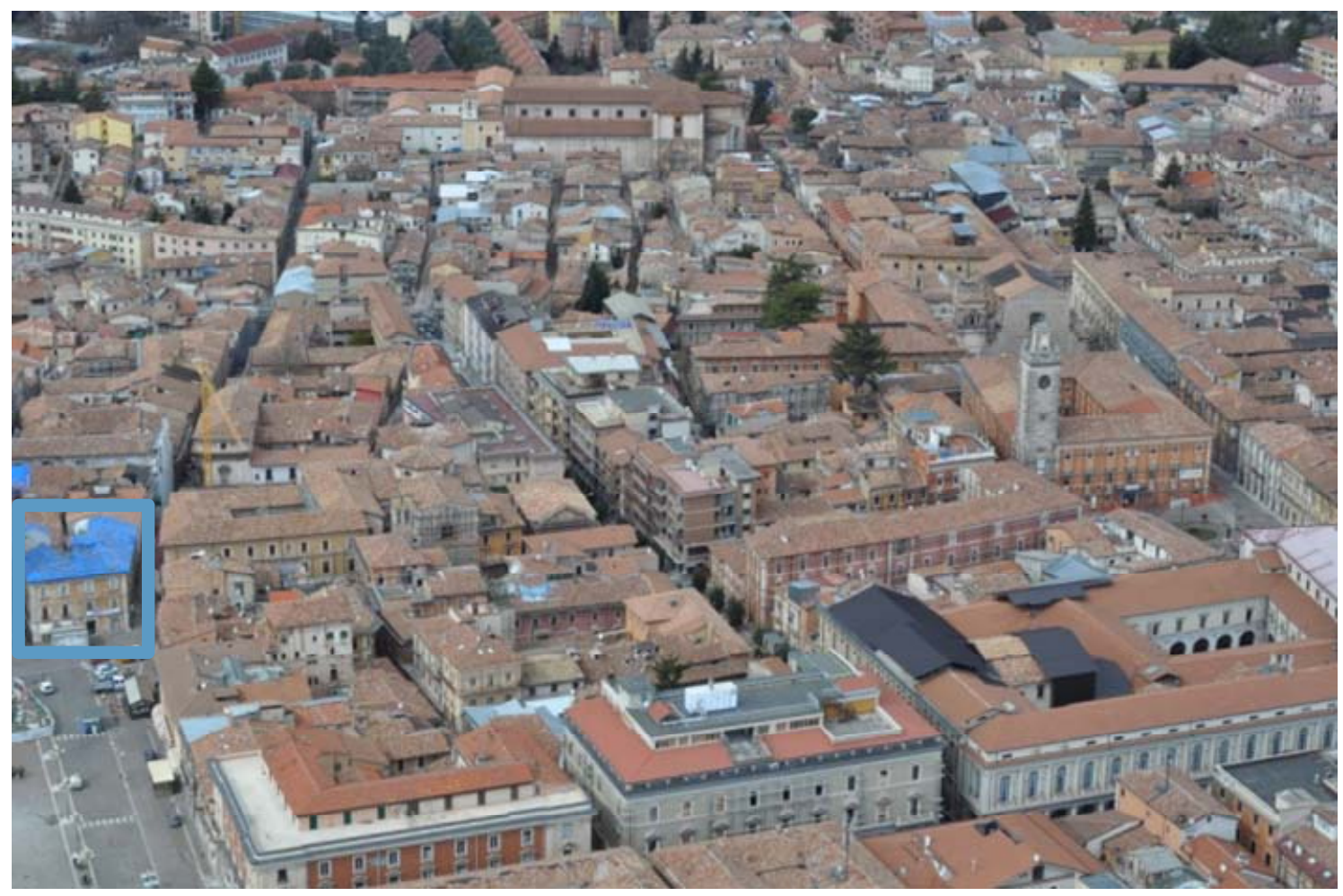

Figure 6. A general view of the area between the Piazza del Duomo and Piazza del Palazzo in March 2012.

even in complete darkness or thick mist. Beyond simple detection, in many cases it is possible to achieve a reliable measurement of the detected temperature by following appropriate protocols.

Although not as widespread as ground-based thermography, airborne thermography is rapidly coming into use. It generally uses more sophisticated sensors, as far as spatial and radiometric resolutions are concerned.

The technique, however, encounters more complex difficulties. There are many factors which could affect measurements; some of them are due to the environment, some others involve the data acquisition process itself. since the flying platform has its own dynamics. Some crucial aspects of an accurate remote measurement of temperature, such as angle of view, focus or sensor stability may easily be affected by perturbing conditions. Several other phenomena may also play a role in prevent-

\footnotetext{
${ }^{1}$ Most commercial thermal cameras can "shoot" an image both in visible-light and in thermal infrared. In our case, however, the thermal camera was only used for capturing thermal frames and a higher resolution digital photo-camera was used to acquire visual images. This dual solution seemed more appropriate since the quality for visual images required by the research was beyond the possibilities of the thermal camera visible light sensor. In our work the digital photo-camera was a Nikon D90 with a $50 \mathrm{~mm}$ optic and image dimensions set to $4288 \times$ 2848 px; the thermal camera was a DALI TEi-P with standard lens and image dimension of $120 \times 160 \mathrm{px}$. The cameras were both mounted on the same hand-held brackets to keep the optics geometrically aligned and only images taken within the same 1 - 2 seconds interval were compared.
}

ing the proper acquisition of data: reflections, vibrations, rapid, strong thermal stresses on the sensor itself. Even in the cases where a high-level mounted system is used, a reliable measurement of temperatures or even a satisfactory thermal map of the scene in front of the sensor could imply the need for ground-based back-up. This means that data acquired by the flying sensor has to be corrected based on direct measurements taken on the ground at specific control points.

These problems can become overwhelming if a handheld commercial thermographic sensor is used to shoot oblique aerial views ${ }^{1}$. It is therefore to be expected that a survey conducted with such tools will not yield reliable thermal measurements, nor consistent thermal maps.

Rather, the process yields a certain amount of data in addition to that coming from the visible light imagery alone, provided that only well defined macro-anomalies are taken into account. Such anomalies are supposed to be reliably detected and distinguished from the frame context in terms of both spatial and radiometric resolutions.

A relevant piece of information in the context of the present study, conducted on L'Aquila and other localities with intensity (MCS) major or equal to 8.5, is the number and approximate distribution of provisional roofing for damaged buildings. In most cases, within the geographical area concerned, such roofing is built in non-painted, sometimes polished metal (in most cases anodized alu- 


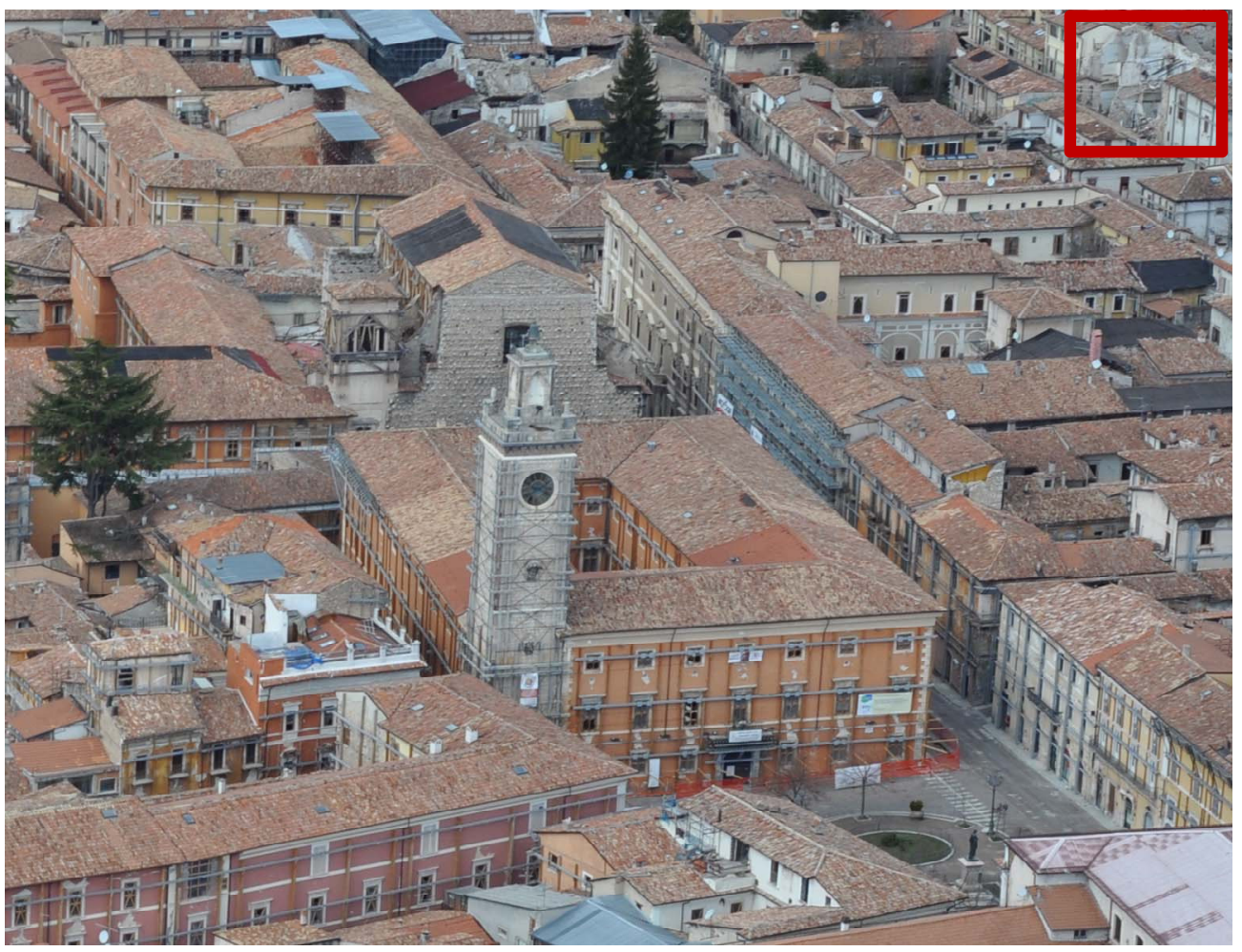

Figure 7. A zoom near Piazza del Palazzo in March 2012.

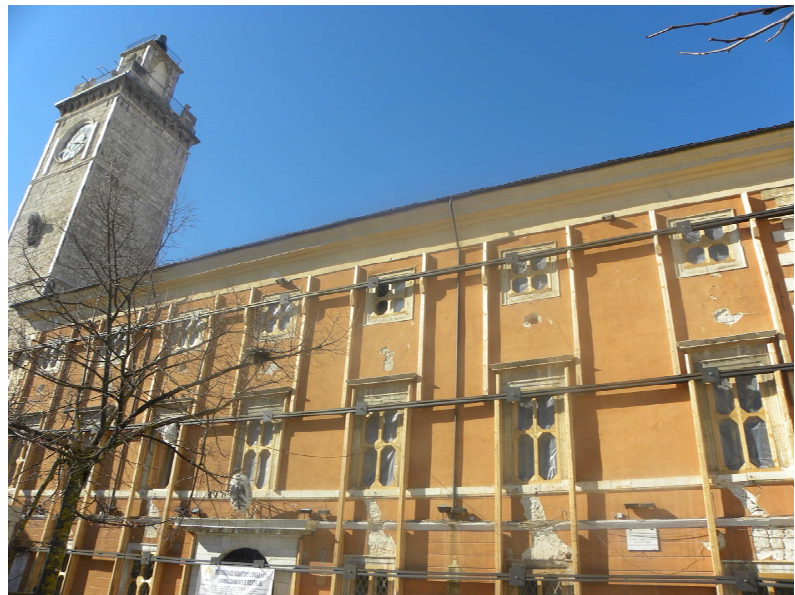

Figure 8. A zoom on Palazzo Margherita (Municipal Office), in Piazza del Palazzo, in February 2010. Photo by C. Pesaresi.

minium). Recognition of these structures may be sometimes difficult in visible light imagery, especially when the reflecting nature of the surfaces might not clearly appear. This is often the case when the sky is overcast and the oblique view is not very angled. However, in a geographic research, the ability of reliably recognizing metal roofing can be significant. In the discussed area, in fact, this type of roofing is an important indication that the building is being repaired/reconstructed; or that temporary enclosure from above is being given to a seriously

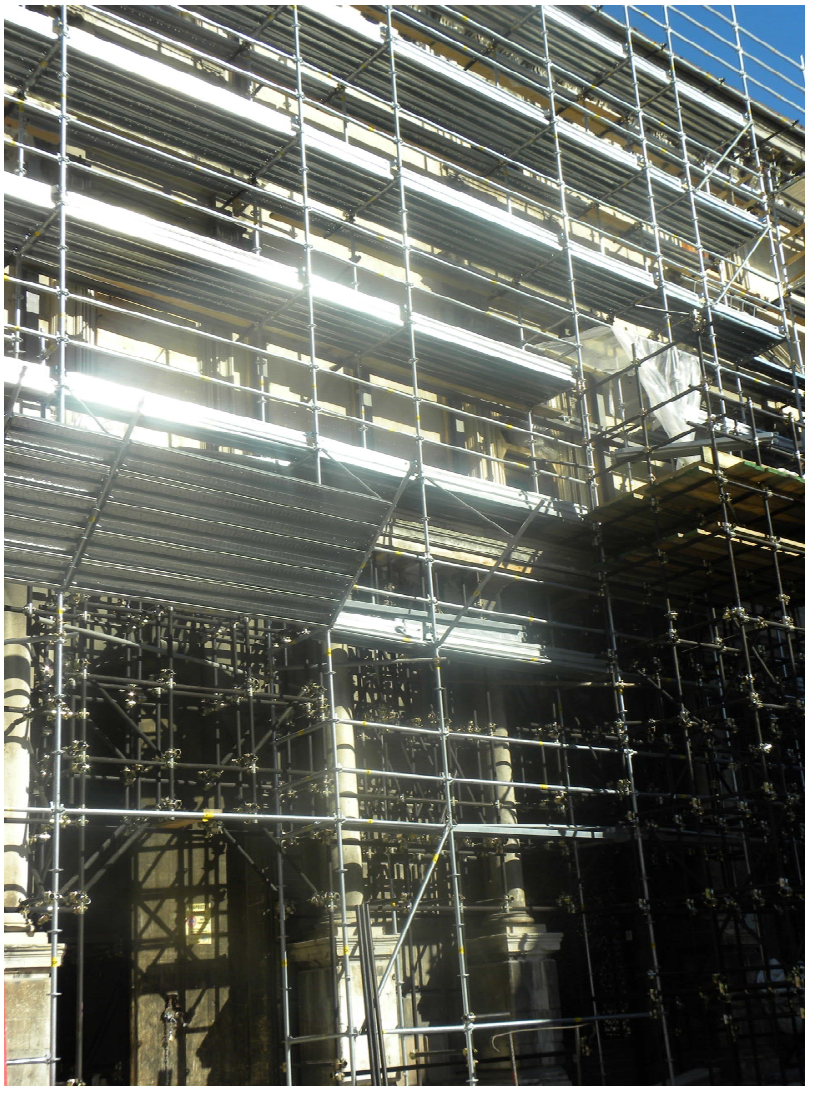

Figure 9. Work of safety measures near Palazzo Madama in February 2010. Photo by C. Pesaresi. 
damaged building, whether or not a repair/reconstruction is planned. The ability to correctly identify and count the examples of this type of structure gives useful information about the damage caused by the earthquake. It also unquestionably indicates that such damage is still to be eliminated by the use of appropriate solutions.

Thermographic photos can prove useful in this type of survey even though the recognition process exploits a "side-aspect" of the thermal camera technology principles. Non-painted metals, have, as a specific property, a low emissivity [18], in comparison to other construction materials. Consequently, in a thermographic frame taken by a sensor set on the standard emissivity coefficient of masonry and cement, non-painted metals will appear extremely "cold", regardless of their real temperature. This thermal indication is so evidently "wrong" that it makes it very easy to recognize what type of material has generated it. Naturally, in a data acquisition process in which so many variables can play a role that is very difficult to account for, there is always the possibility of "false-positives". Nevertheless, the quantitative difference between the indicated temperatures of non-painted metals and those of the other materials is so wide and so easily identifiable in most cases, that the recognition process could possibly be automated by implementing a fairly simple comparative algorithm. In this case, reference to the visible-light images could be limited to the analyst's supervision.

In our case, we used the comparison between light images and thermographic frames first of all to have some preliminary information on the distribution of the provisional non-painted metal roofing of buildings in L'Aquila and in the other localities with intensity (MCS) major or equal to 8.5 , in order to quickly obtain an indication on where attention has to be focused. For example, if we consider L'Aquila seen in visible-light (Figure 10(a)) and in thermal infrared (Figure 10(b)) we have the kind of information which immediately shows the presence of damages and provisional covering. Particularly, the scale on the right of the thermographic frame indicates the apparently "freezing-cold" surface temperature of nonpainted metal roofs on top of seriously damaged buildings. This is a "wrong" indication due to the very low emissivity of the material but at the same time it is very important in indicating where these kinds of provisional roofs are. The comparison with the corresponding visible-light image confirms this data and allows us to obtain geographical information that is also useful in interdisciplinary studies.

\section{Conclusions}

In order to make an accurate analysis of the actual situation in L'Aquila town centre-which can be considered a significant example of a "City of Stone" almost "minus" the presence of people- and in the other localities with intensity (MCS) major or equal to 8.5, we have tested a geographical methodology supported by the use of geotechnologies. This methodology, which involves different steps, the use of various images in visible and thermal light and the combination of overflight and field studies, has allowed us to provide a general and detailed overview of the current situation in the areas most damaged by the earthquake of 6 April 2009.

In this case, we focus particular attention on L'Aquila town centre which can be seen as a very interesting laboratory with disquieting social and economic problems

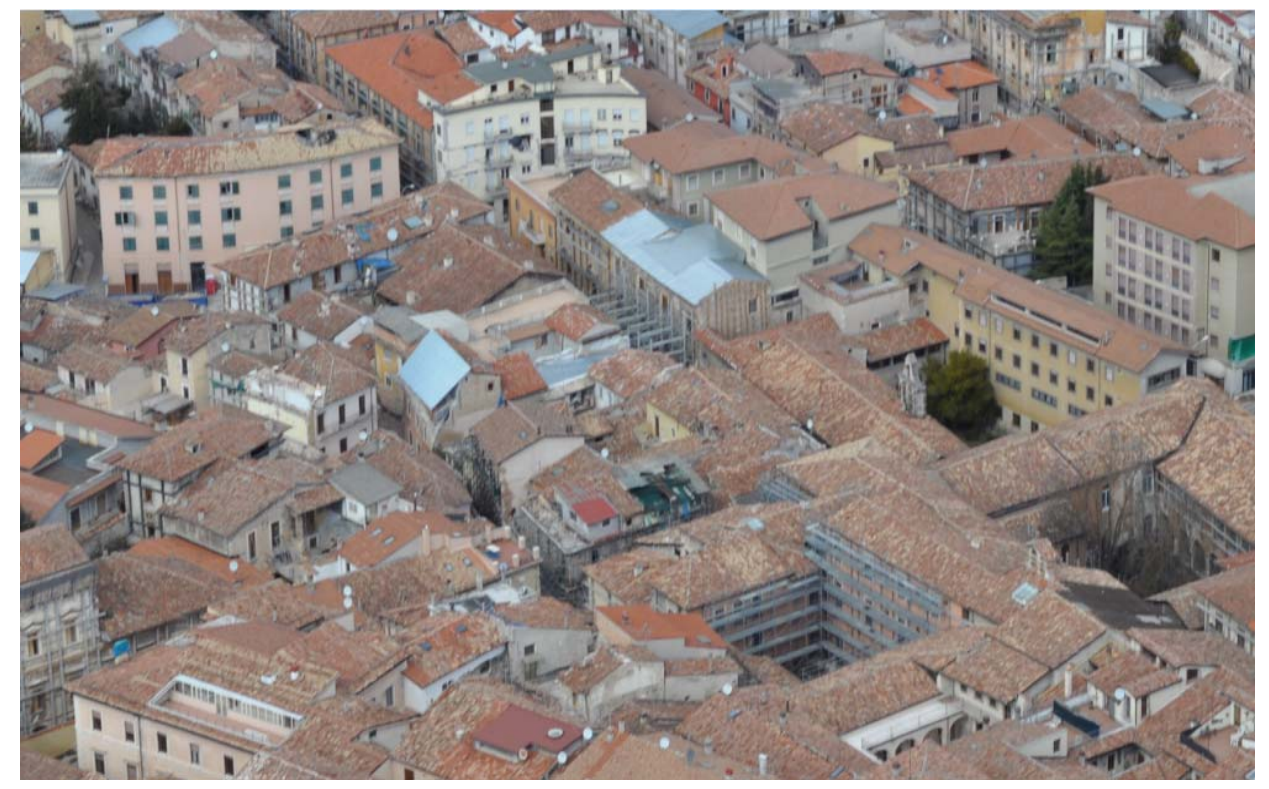

(a) 


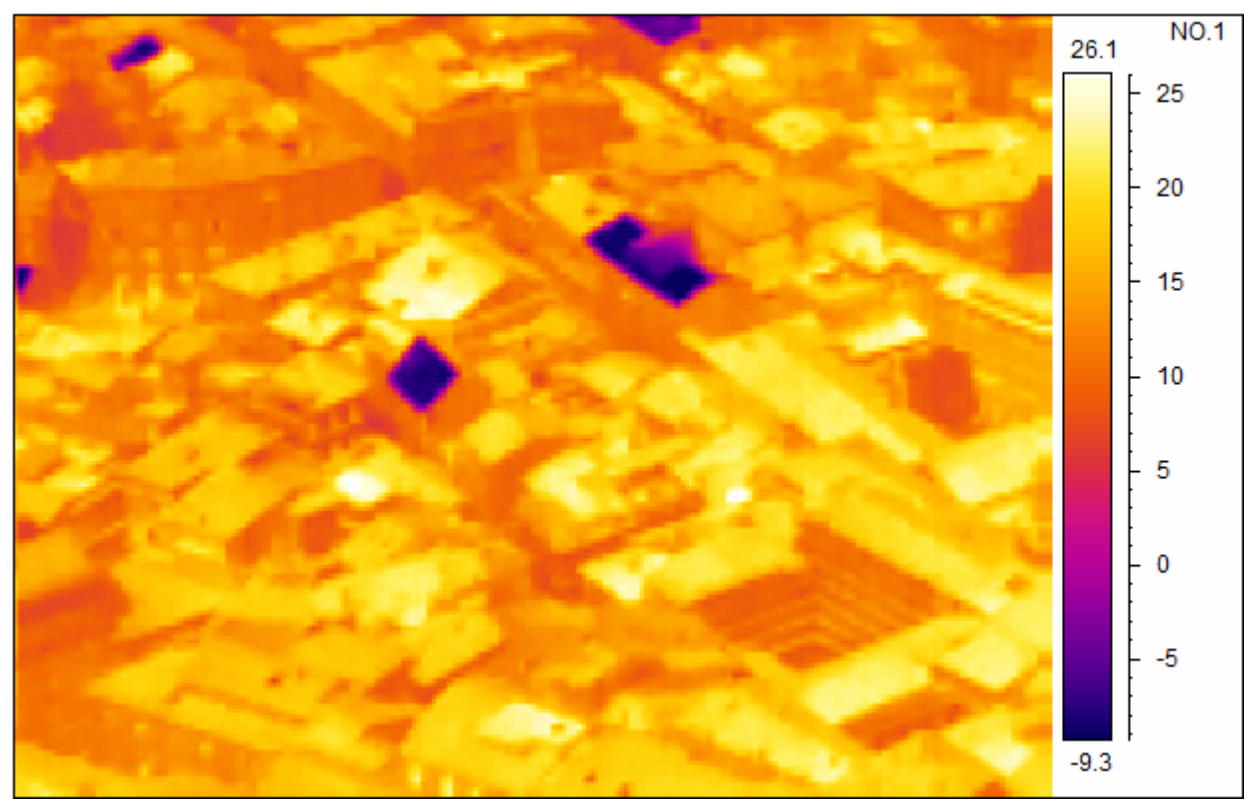

(b)

Figure 10. A central urban area of L'Aquila, seen in visible-light (a) and in thermal infrared (b).

provoked by the earthquake and which have not been solved by the policies adopted.

Therefore, the images and the approach used in this paper show that L'Aquila town centre, three years after the earthquake, appears as a heavily damaged urban context which requires practical, widespread and specific intervention necessary for a general re-vitalization which can: repair essential services and economic activities; reprovide a sense of identity to the community; re-establish a sense of balance which is currently lacking (also because the damaged buildings continue to have a provisional status); and recover a historical and cultural heritage which symbolises the pride of the people of L'Aquila.

The leitmotiv of the tested methodology and geographical analysis has been to conduct a research useful to society and to Local Authorities, providing input in different directions and pursuing a spatial-temporal criteria.

\section{Acknowledgements}

Even if the paper was devised together by the authors, C. Pesaresi wrote paragraphs 2, 3 and 5, G. Casagrande wrote paragraph 4, R. Morri wrote paragraph 1 . The authors thank Aviogestioni Sportive S.r.l. for the technical support.

\section{REFERENCES}

[1] G. Forino, "Riflessioni Geografiche sul Disaster Management all’Aquila,” In: C. Pesaresi, Ed., L'Aquila e il Cratere Sismico. Le Cause e le Conseguenze del Terremoto (6 aprile 2009) in Chiave Applicativa e Interdisciplinare, Semestrale di Studi e Ricerche di Geografia, Roma, in
Press.

[2] F. Cristaldi and R. Morri, “A New Social Map of Metropolitan Areas: The Case of City Users and City Businessmen in Rome," Semestrale di Studi e Ricerche di Geografia, Roma, 2003.

[3] S. Leonardi, “Aquila bella mè...” In: C. Pesaresi, Ed., L'Aquila e il Cratere Sismico. Le Cause e le Conseguenze del Terremoto (6 aprile 2009) in Chiave Applicativa e Interdisciplinare, Semestrale di Studi e Ricerche di Geografia, Roma, in Press.

[4] F. Farinelli, "Estetizzazione ed anestizzazione," In: C. Andriani, Ed., Il Patrimonio e l'Abitare, Donzelli, Roma, 2010.

[5] E. Scandurra, "Ripensare l’Urbanistica: Periferie,” In: F. Scarpelli and A. Romano, Eds., Voci Della Città, Carocci, Roma, 2011.

[6] F. Scarpelli and A. Romano, Eds., "Voci Della Città,” Carocci, Roma, 2011.

[7] M. Maggioli and R. Morri, "Periferie Urbane: Tra Costruzione dell’Identità e Memoria,” Geotema, Vol. 37, 2009, pp. 62-69.

[8] G. Casagrande and C. Pesaresi, "Analisi Geografiche, con Fotocamera e Termocamera, per lo Studio di L’Aquila e del Cratere Sismico,” In: C. Pesaresi, Ed., L'Aquila e il Cratere Sismico. Le Cause e le Conseguenze del Terremoto (6 aprile 2009) in chiave applicativa e interdisciplinare, Semestrale di Studi e Ricerche di Geografia, Roma, in Press.

[9] P. Galli and R. Camassi, Eds., "Rapporto Sugli Effetti del Terremoto Aquilano del 6 aprile 2009,” Report DPCINGV, 2009.

[10] C. Pesaresi and F. Nebbia, "L’Aquila e Onna, un Anno Dopo il Terremoto del 6 Aprile 2009," Geografia, Vol. 3-4, 2010, pp. 32-51. 
[11] Ö. Aydan, H. Kumsar and S. Toprak, “The 2009 L'Aquila Earthquake (Italy): Its Characteristics and Implications for Earthquake Science and Earthquake Engineering," Journal of the Earth Sciences Application and Research Centre of Hacettepe University, Vol. 30, No. 3, 2009, pp. 235-257.

[12] H. Kaplan, H. Bilgin, S. Yilmaz, H. Binici and A. Öztas, "Structural Damages of L'Aquila (Italy) Earthquake," Natural Hazards and Earth System Sciences, Vol. 10, 2010, pp. 499-507. doi:10.5194/nhess-10-499-2010

[13] P. Bazzurro, D. Alexander, P. Clemente, M. Comerio, A. De Sortis, F. Filippou, A. Goretti, M. Jorjani, F. Mollaioli, K. M. Mosalam, J. Price and M. Schotanus, "Learning from Earthquakes. The Mw 6.3 Abruzzo, Italy, Earthquake of April 6, 2009,” EERI Special Earthquake Report, 2009.

[14] G. Camata, S. Biondi, G. De Matteis, C. G. Lai, E. Spa- cone, I. Vanzi and M. Vasta, "Post Damage Assessment of the L'Aquila, Abruzzi April 6, 2009 Earthquake, Thematic Conference on Computational Methods in Structural Dynamics and Earthquake Engineering," COMPDYN, Rhodes, 2009.

[15] A. B. Liel and K. P. Lynch, "Vulnerability of Reinforced Concrete Frame Buildings and Their Occupants in the 2009 L’Aquila, Italy Earthquake,” Quick Response Report, Natural Hazards Center, 2009.

[16] A. M. Reggiani, “Il Patrimonio Ferito dell'Aquila," ROMVLA, Vol. 10, 2011, pp. 307-342.

[17] G. Roche, “La Termografia per l’Edilizia e l'Industria. Manuale Operativo per le Verifiche Termografiche,” Maggioli Editore, Santarcangelo di Romagna, 2012.

[18] D. Lanzoni, "Diagnosi e Certificazione Energetica: Prove Strumentali Sugli Edifici,” Maggioli Editore, Santarcangelo di Romagna, 2010. 